\title{
Experimental verification of the linear and non-linear versions of a panel code
}

\author{
G.J. Grigoropoulos, C. Katsikis and D.S. Chalkias
}

School of Naval Architecture and Marine Engineering, National technical University of Athens, Greece

\begin{abstract}
In the proposed paper numerical calculations are carried out using two versions of a three-dimensional, timedomain panel method developed by the group of Prof. P. Sclavounos at MIT, i.e. the linear code SWAN2, enabling optionally the use of the instantaneous non-linear Froude-Krylov and hydrostatic forces and the fully non-linear SWAN4. The analytical results are compared with experimental results for three hull forms with increasing geometrical complexity, the Series 60, a reefer vessel with stern bulb and a modern fast ROPAX hull form with hollow bottom in the stern region. The details of the geometrical modeling of the hull forms are discussed. In addition, since SWAN4 does not support transom sterns, only the two versions of SWAN2 were evaluated over experimental results for the parent hull form of the NTUA double-chine, wide-transom, high-speed monohull series. The effect of speed on the numerical predictions was investigated. It is concluded that both versions of SWAN2 the linear and the one with the non-linear Froude-Krylov and hydrostatic forces provide a more robust tool for prediction of the dynamic response of the vessels than the non-linear SWAN4 code. In general, their results are close to what was expected on the basis of experience. Furthermore, the use of the option of non-linear Froude-Krylov and hydrostatic forces is beneficial for the accuracy of the predictions. The content of the paper is based on the Diploma thesis of the second author, supervised by the first one and further refined by the third one.
\end{abstract}

KEY WORDS: Seakeeping; Panel method; Model tests; Non-linearity; Time-domain.

\section{INTRODUCTION}

Following the pioneering works of Ursell (1949a, 1949b) on the two-dimensional motions of a cylinder in waves, Korvin-Kroukovsky (1955) developed the first practical method to predict analytically the seakeeping performance of a ship in waves. The method denoted as strip theory is based on the two-dimensional (2-D) hydrodynamic characteristics of the ship's sections and it is widely used for the evaluation of the seakeeping qualities of ships. The ship's sections are either mapped onto circular sections to implement Ursell's solutions, using Lewis (Lewis, 1929) or Extended-Lewis (Athanassoulis and Loukakis, 1982) conformal mapping techniques or are fitted with fundamental wave singularities or Wave Green Functions (WGF) along the wetted contour (Frank, 1967). Later on, more exact and rigorous versions of the strip theory, as well as alternative two-dimensional techniques have been proposed. Their presentation, however, is outside the scope of this paper.

In the 80s three-dimensional theories for zero speed were developed (Guevel and Bougis, 1982). The forward speed in that case is treated in the same way as in the strip theory. At

Corresponding author: Grigoropoulos, G.J.

e-mail: gregory@central.ntua.gr the same time fully three-dimensional methods were proposed, using either the translating and pulsating Kelvin source (see e.g. Liapis, 1986), which satisfies the free surface condition, or the simple Rankine source i.e. an elementary singularity for infinite-domain potential flows (Sclavounos, 1996). The latter methods provide more promising results than the former.

In this paper numerical calculations are carried out by means of SWAN2, a 3-D, time-domain panel code (Sclavounos, 1996) in its fully linear version as well as using the instantaneous non-linear Froude-Krylov and hydrostatic forces (Kring, 1994 and Kring et al., 1995), and SWAN4, a non-linear code (Huang, H-F, 1997) for three hull forms with increasing geometrical complexity, the Series 60, a reefer vessel with stern bulb and a modern fast ROPAX hull form with hollow bottom in the stern region. The SWAN4 code uses the weak-scatterer hypothesis for the calculation of the Froude-Krylov and the restoring forces. The numerical results are compared with experimental ones. Some minor geometrical modifications applied on the hull forms during the modeling are discussed. In addition numerical results using the two versions of SWAN2 code for the parent hull form of the NTUA double-chine wide-transom, high-speed monohull series are evaluated using experimental results. The effect of speed on the numerical predictions was investigated. Currently, SWAN4 does not support transom sterns. 


\section{TEST CASES}

\section{Series-60 hull form}

As first test case the central Series-60 hull form was selected. The body plan of the hull form is shown on Fig. 1 and the main particulars on Table 1. This hull form is representative of simple and conventional hull forms and is used as test case in most of the comparative studies as well as in the User Manuals of the pertinent software.

Table 1 Main Particulars of the Series-60 hull form.

\begin{tabular}{|c|c|}
\hline$L_{O A}$ & $103.8 m$ \\
\hline$L_{B P}$ & $100 m$ \\
\hline$B$ & $14.28 m$ \\
\hline$D$ & $8.55 m$ \\
\hline$T$ & $5.7 m$ \\
\hline$\Delta$ & $5854 t o n s$ \\
\hline$V_{S}$ & $12.2 k t s$ \\
\hline$C_{B}$ & 0.7 \\
\hline
\end{tabular}

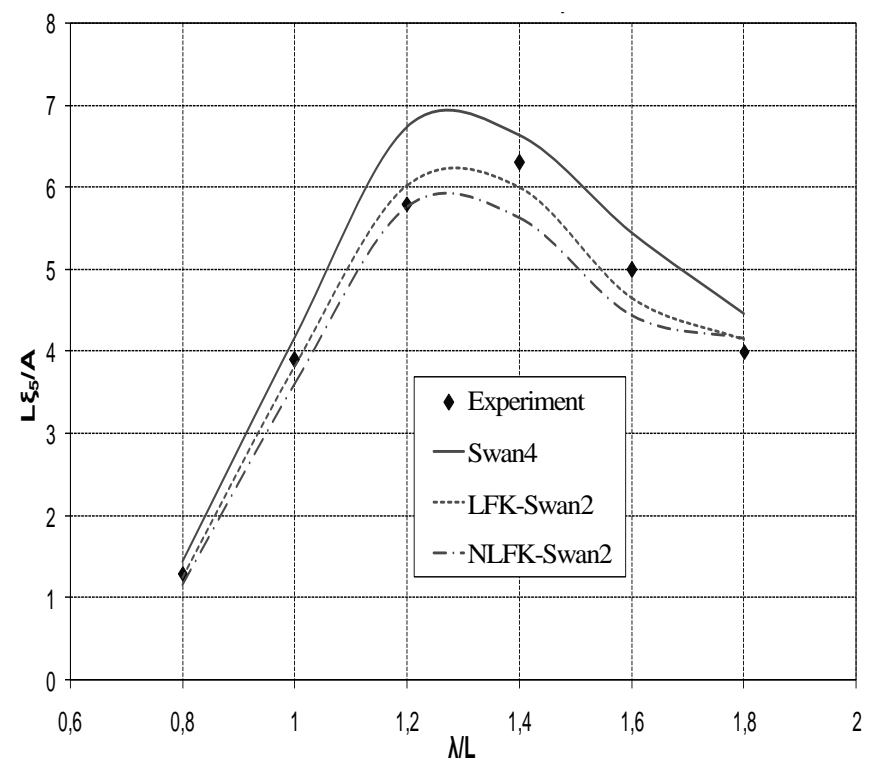

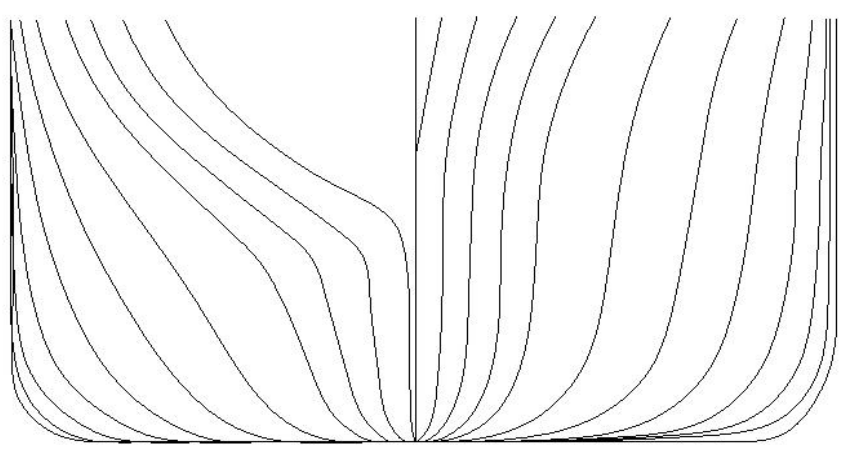

Fig. 1 Body plan and main particulars of Series 60 hull form

In order to compare the behavior of the three versions of SWAN in this relatively simple geometry, calculations using all these versions have been carried out for a speed corresponding to Froude numbers $F n=0.20,0.25$ and 0.30 , at head waves with length over ship length ratios $\lambda / L$ in the 0.80 to 1.80 range. The length between perpendiculars stands for $L$ in the aforementioned ratios. The fully linear execution of SWAN2 is denoted as LFK, while the one where the nonlinear Froude-Krylov and hydrostatic forces are used as NLFK. All numerical tests refer to a wave amplitude $A=$ $L / 100$. The heave and pitch RAOs are presented in Fig. 2.

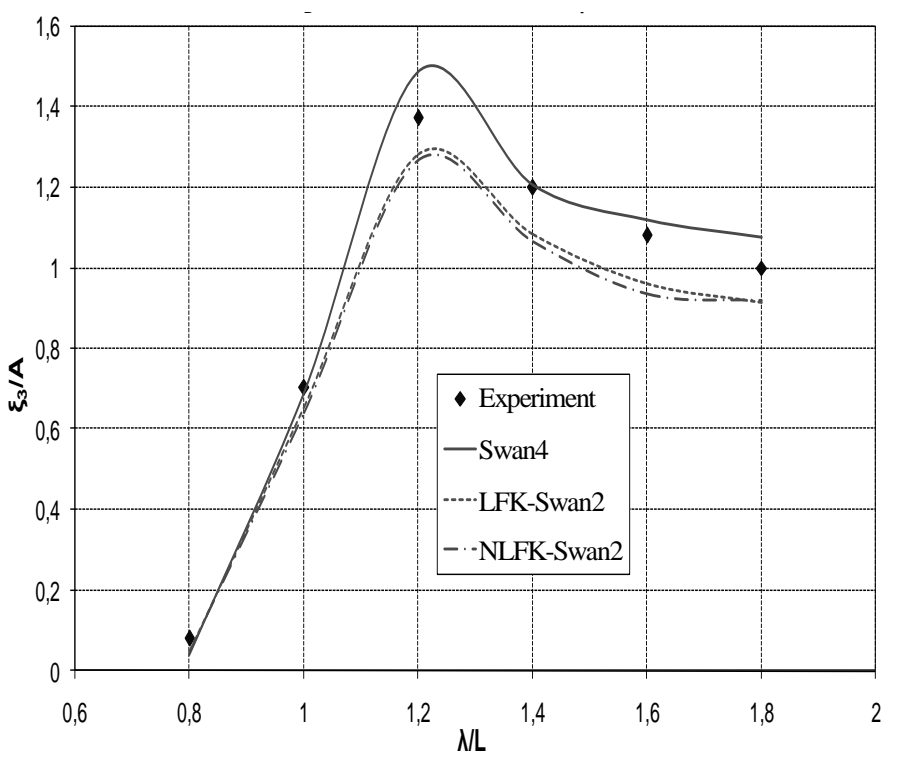

Fig. 2 Heave and pitch RAOs for the Series 60 hull form using both versions of SWAN2 and SWAN4 compared with experimental results provided by Gerritsma et al. (1974); $C_{B}=0.7, A / L=0.01, F n=0.2, B=180^{\circ}$.

The experimental results were provided by Gerritsma et al. (1974). Additional runs in head waves have been conducted at speeds with $F n=0.25$ and 0.30 using SWAN4. In this way, the effect of speed on the performance of this non-linear code is investigated. The respective results have been plotted on Fig. 3. Following Fig. 2 SWAN4 provides results in closer agreement with the experimental ones than SWAN2, while the fully linear SWAN2 is better in pitch assessment. The speed increase shifts the peak of both the heave and pitch RAOs to longer encountered waves and raises the value of the peak response, especially for heave.

Finally, in Fig. 4 the time histories for the vertical force and the moment around the lateral y-axis using all three codes are presented. The oscillatory behavior of the time history derived by SWAN4 has also been noted by other researchers (see e.g. Kim and Kim, 2009) 

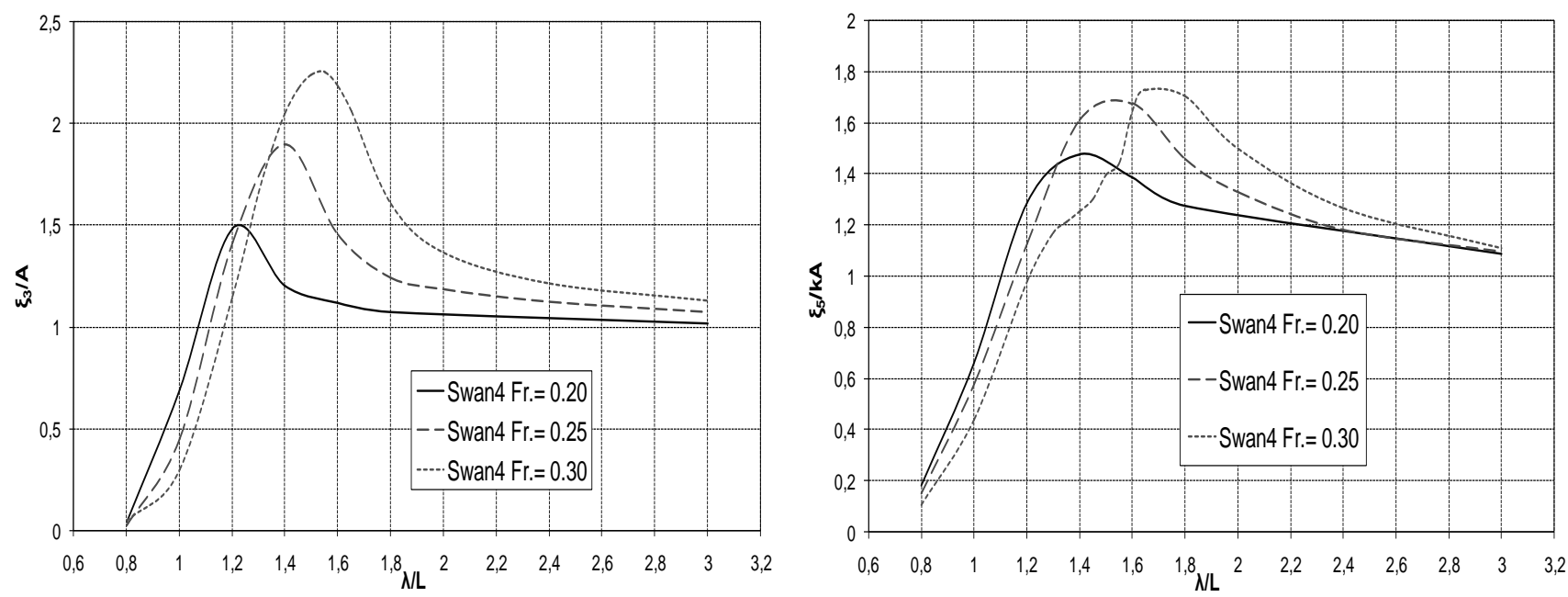

Fig. 3 Heave and pitch RAOs for the Series 60 hull form using SWAN4 for speeds corresponding to $F n=0.20,0.25$ and 0.30 ; $C_{B}=0.7, A / L=0.01, \beta=180^{\circ}$.
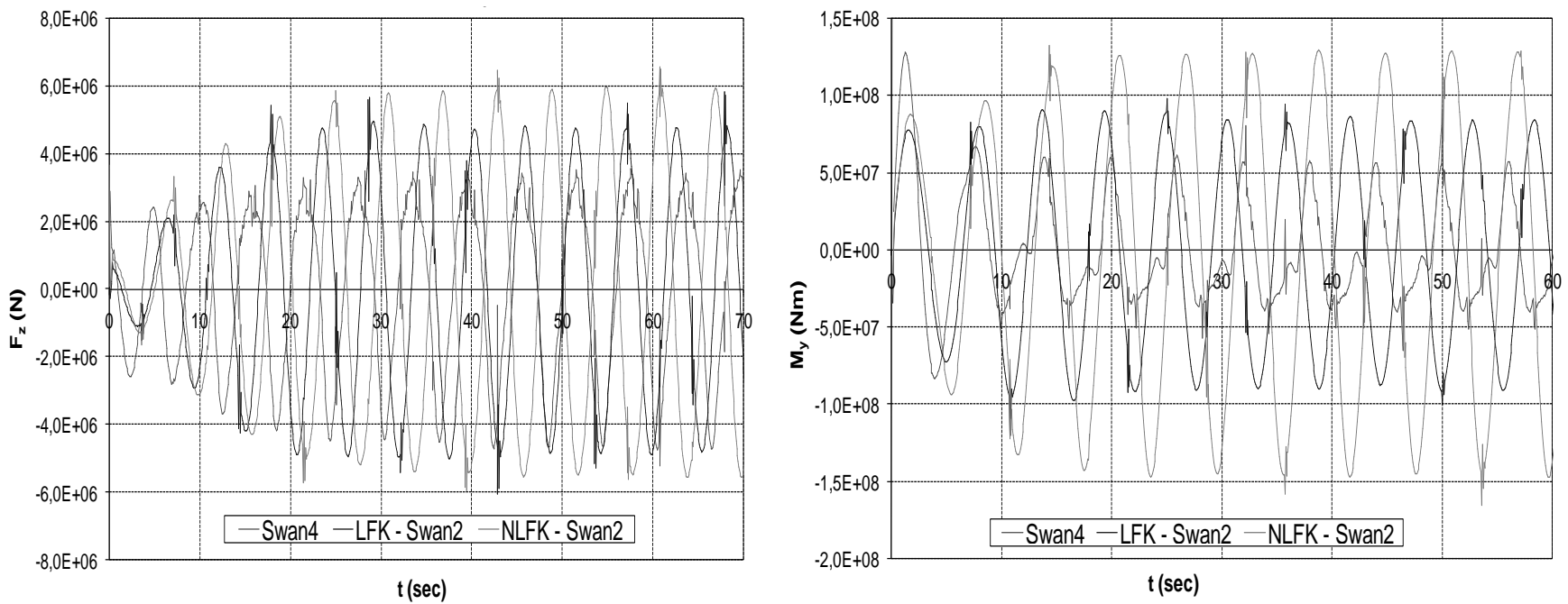

Fig. 4 Time histories of vertical force and moment about the lateral $y$-axis for the Series 60 hull form using both versions of SWAN2 and SWAN4; $F n=0.20, C_{B}=0.7, A / L=0.01, \beta=180^{\circ}$.

\section{Reefer hull form}

As a second test case the hull form a reefer vessel has been used. This hull form has been used for optimization purposes in the Laboratory for Ship and Marine Hydrodynamics (LSMH) of the National Technical University of Athens (NTUA) (Grigoropoulos, 2004). The bow bulb has been extracted from the hull form tested in the Towing Tank of LSMH/NTUA and, the same holds true in the numerical simulations. However, there is a stern bulb on the hull form. The body plan and the stern region of the hull form are given in Fig.5 and the main particulars in Table 2. In order to compare the behavior of the three versions of SWAN in this more complicated geometry, calculations using all these versions have been performed for two speeds with $F n=0.24$ and 0.29 , at head waves with length over ship length ratios $\lambda / \mathrm{L}$ in the 0.60 to 2.20 range. All numerical and experimental tests refer to wave amplitudes $A=L / 100$. The heave and pitch
RAOs are presented in Figs. 6 and 8 for $F n=0.24$ and 0.29, respectively. The absolute vertical accelerations for both speeds are shown on Fig. 7. In this way the effect of speed on the performance of the codes is investigated.

Table 2 Main Particulars of the Reefer hull form.

\begin{tabular}{|c|c|}
\hline$L_{O A}$ & $103 m$ \\
\hline$L_{B P}$ & $93.4 m$ \\
\hline$B$ & $17 m$ \\
\hline$D$ & $9.65 m$ \\
\hline$T$ & $6.5 m$ \\
\hline$\Delta$ & $6464 t o n s$ \\
\hline$V_{S}$ & $17 k t s$ \\
\hline$C_{B}$ & 0.577 \\
\hline
\end{tabular}



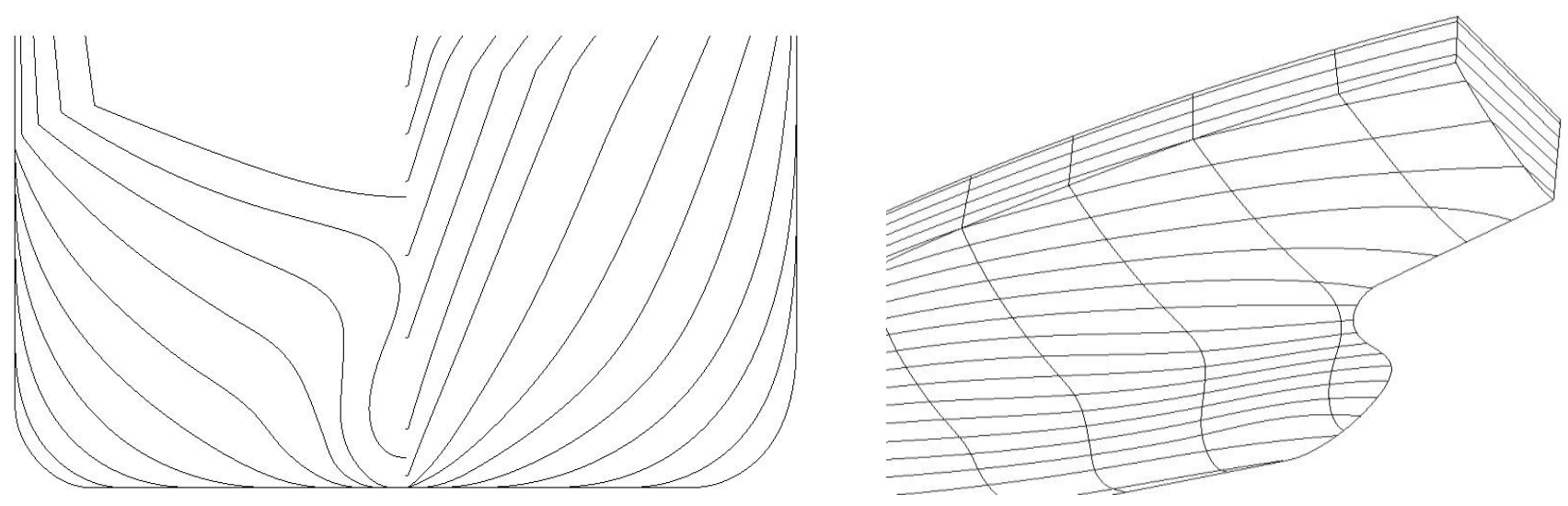

Fig. 5 Body plan, perspective view of the stern region and main particulars of reefer hull form.
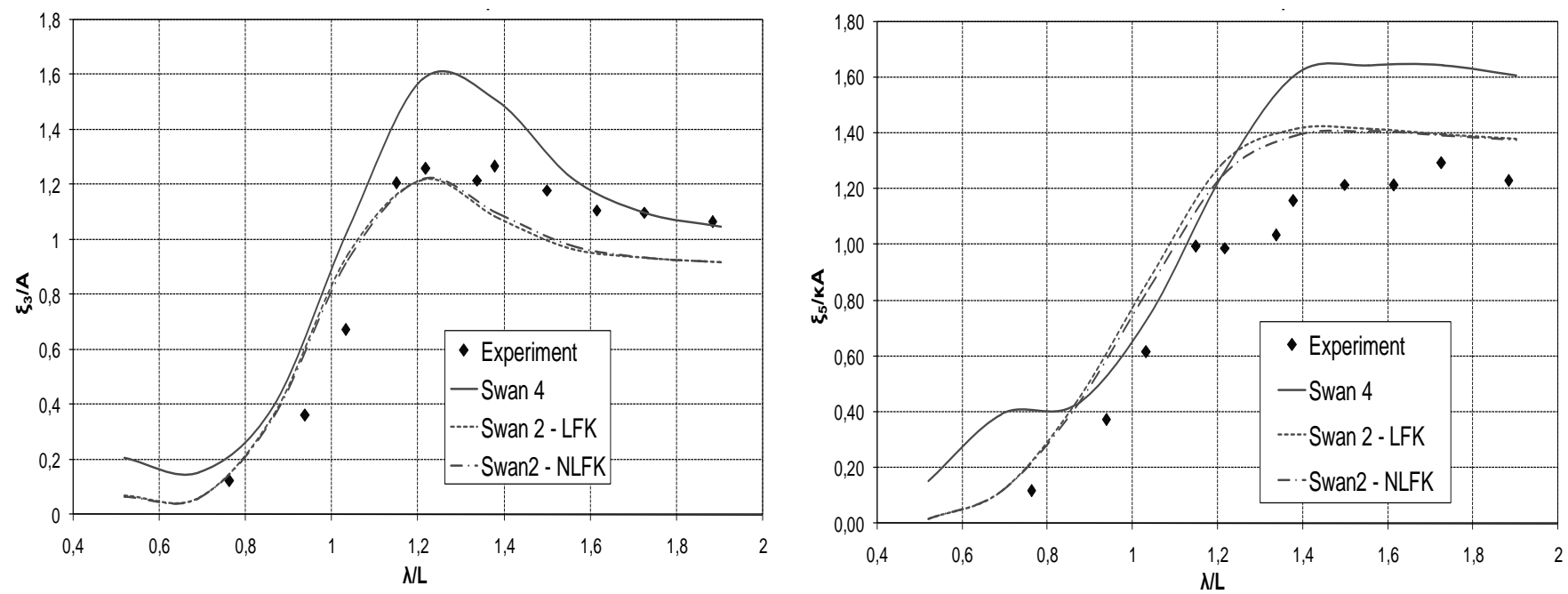

Fig. 6 Heave and pitch RAOs for the reefer hull form using all three versions of SWAN and NTUA experimental results for a speed with $F n=0.24, C_{B}=0.7, A / L=0.01, B=180^{\circ}$.
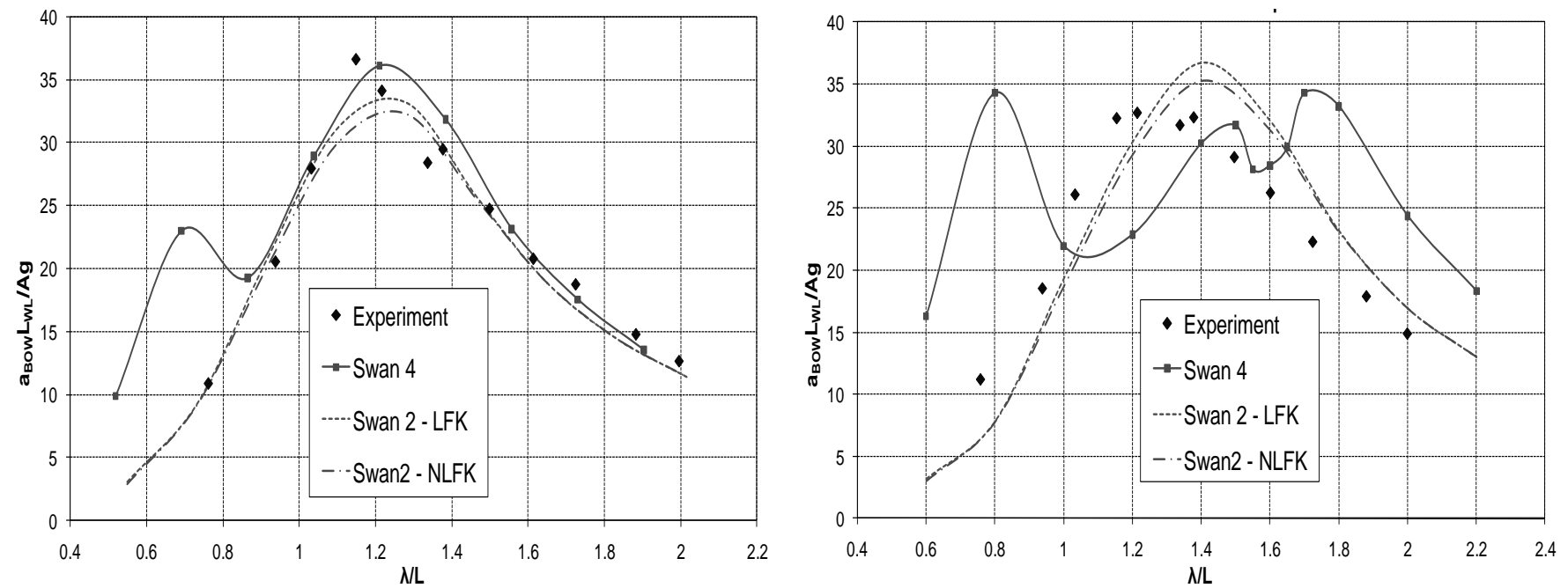

Fig. 7 RAO of vertical acceleration at the bow of the reefer hull form using all three versions of SWAN and NTUA experimental results for speeds with $F n=0.24,0.29, C_{B}=0.7, A / L=0.01, \beta=180^{\circ}$. 

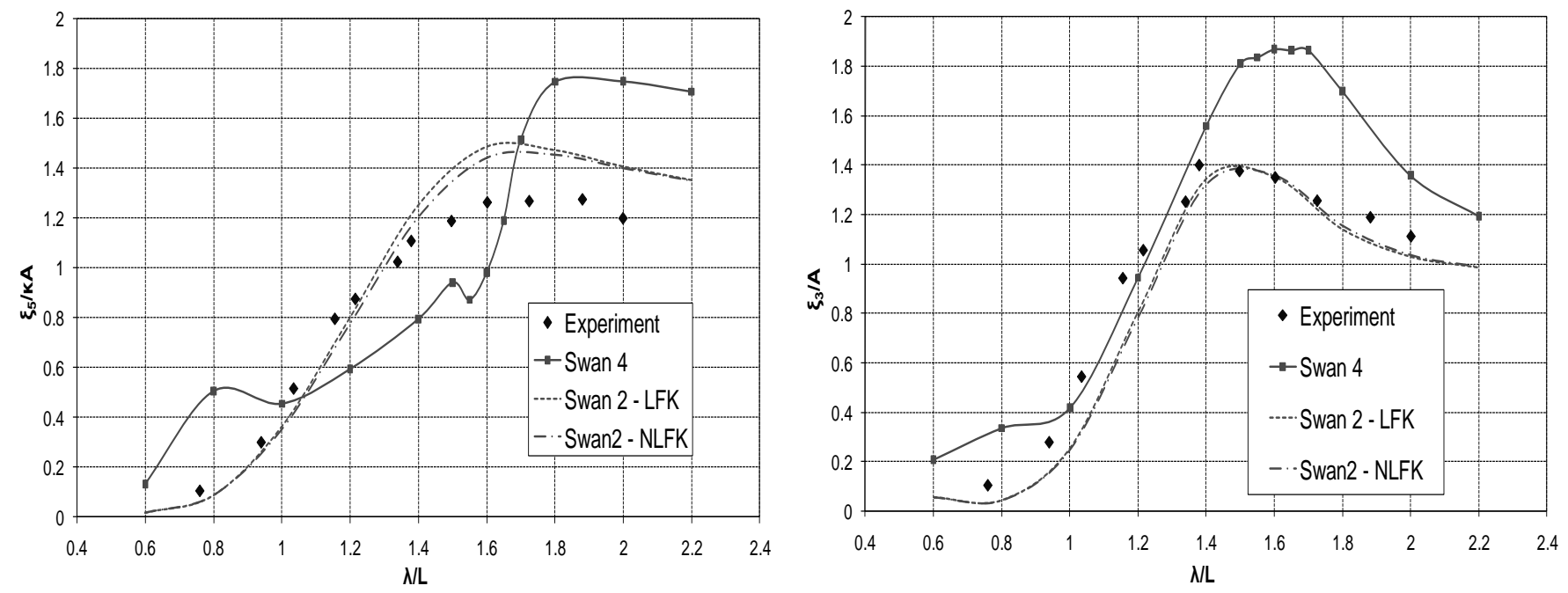

Fig. 8 Heave and pitch RAOs for the reefer hull form using all three versions of SWAN and NTUA experimental results for a speed with $F n=0.29, A / L=0.01, \beta=180^{\circ}$.

\section{ROPAX hull form}

As a third test case the quite complex hull form of a modern fast ROPAX (ferry) has been used. This hull form incorporates a bow bulb which has been optimized for calm water resistance in NTUA/LSMH (Grigoropoulos and Chalkias, 2005). The body plan and a perspective view of the

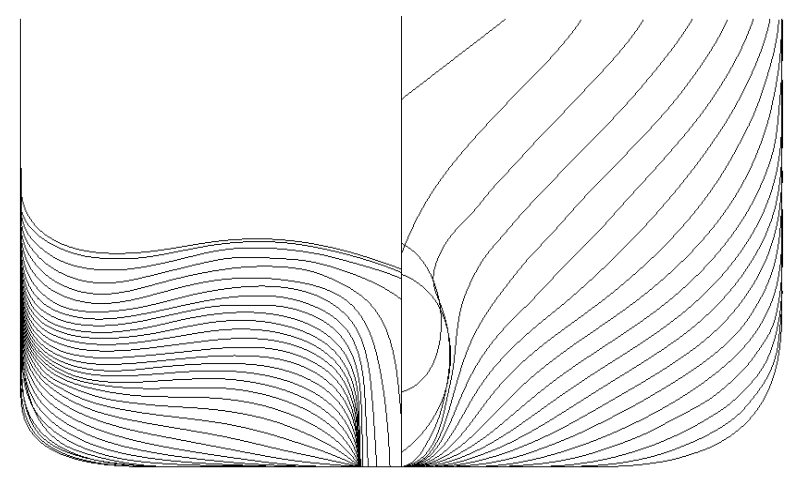

(a) The left side

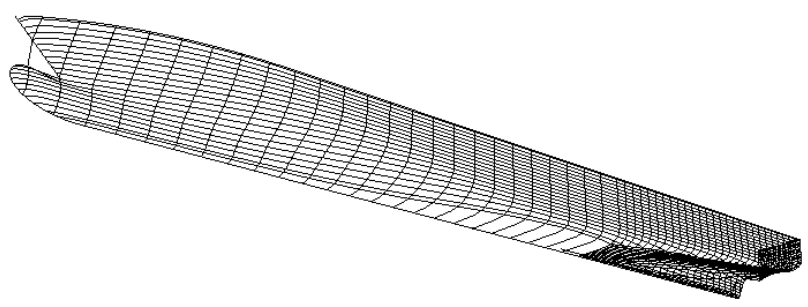

(c) Perspective view hull form are presented in Fig.9 and the main particulars are given in Table 3.

As it is depicted in the upper left body plan of Fig. 9, the lines of the sections in the stern region are hollow (concave) in their bottom. These lines can't be modeled properly in any version of SWAN code, so the modified lines of the upper right body plan in Fig. 9 have been used instead.

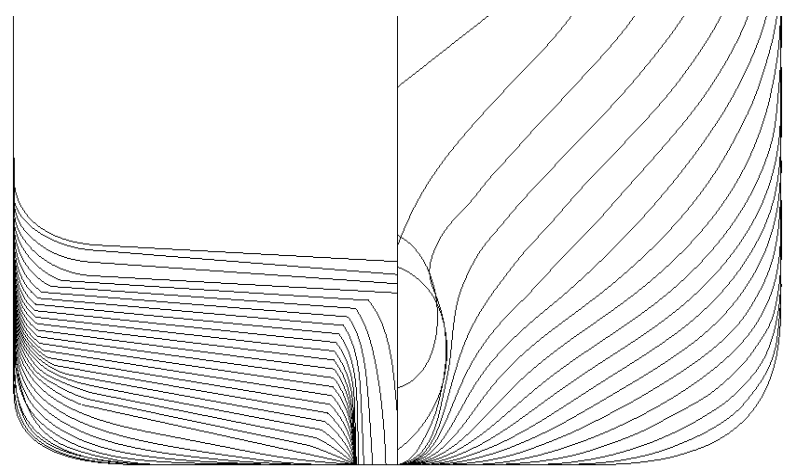

(b) The right side

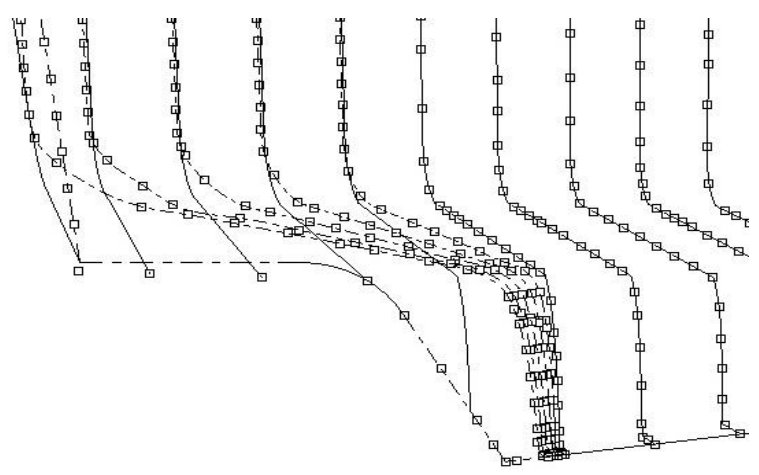

(d) Input fed to SWAN4

Fig. 9 Body plan of the ROPAX hull form. 
Table 3 Main Particulars of the ROPAX hull form.

\begin{tabular}{|c|c|}
\hline $\mathrm{L}_{\mathrm{OA}}$ & $194 m$ \\
\hline$L_{B P}$ & $188.5 m$ \\
\hline$B$ & $25 m$ \\
\hline$D$ & $14.5 \mathrm{~m}$ \\
\hline$T$ & $6.5 m$ \\
\hline$\Delta$ & 17000 tons \\
\hline$V_{S}$ & $28.5 \mathrm{kts}$ \\
\hline$C_{B}$ & 0.53 \\
\hline
\end{tabular}

In the modified drawing the hollow lines have been replaced by straight lines. Furthermore, the hull form possesses high flare in the bow region, near the deck line and a slightly submerged transom section. Since the transom stern can't be modeled within SWAN4, we used beveling in the definition of stern sections and slight forward shift of the

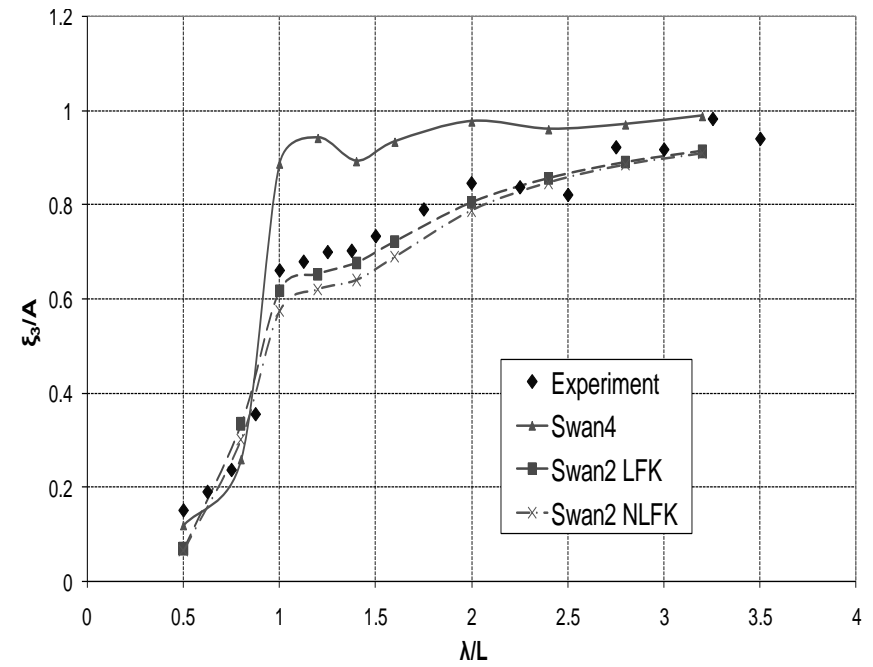

transom side by $0.40 \mathrm{~m}$ at the deck, to simulate a conventional stern, where the uppermost point of the profile is the aftermost point of the hull (Fig. 9).

Following Figs. 6 to 8, both SWAN2 versions perform better than SWAN4 for heave and more reasonably for pitch response. According to Fig. 7, the predictions of all codes at the lower speed are reasonable except for SWAN4 at the lower wave length range. At the higher speed SWAN4 fails to predict the RAO curve, while both versions of SWAN2 provide reasonable but not satisfactory results.

All three versions of SWAN have been evaluated in this quite complicated geometry. Calculations using all these versions have been performed for two speeds with $F n=0.26$ and 0.33 , at head waves with length over ship length ratios $\lambda / \mathrm{L}$ in the 0.50 to 3.20 range. All numerical and experimental tests refer to wave amplitude $A$ equal to $1.3 \mathrm{~L} / 100$. The heave and pitch RAOs are presented in Fig.10 and 12 for $F n=0.26$ and 0.33 , respectively. In Fig. 11, the RAO of the vertical acceleration at the bow for both speeds is plotted.

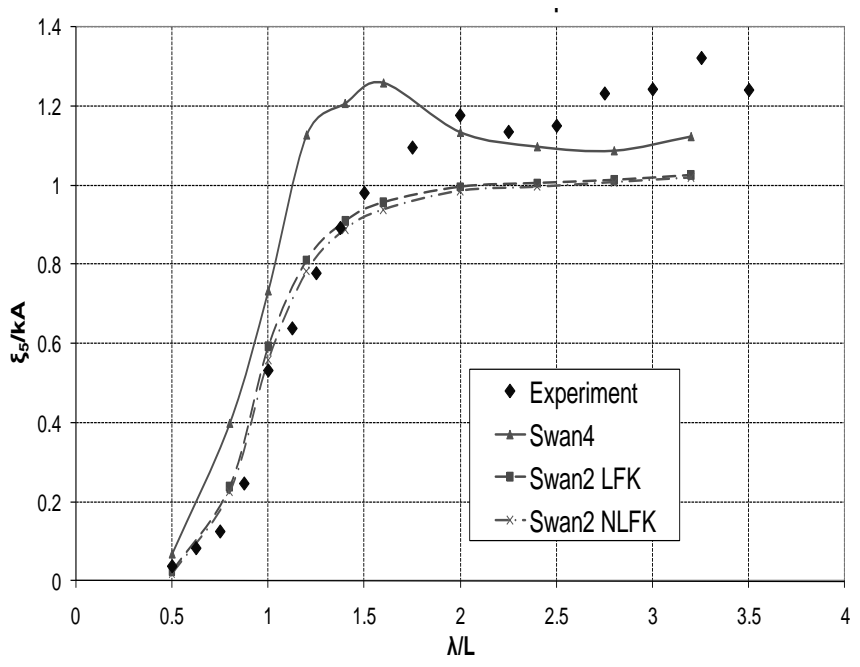

Fig. 10 Heave and pitch RAOs for the fast ROPAX hull form using all three versions of SWAN and NTUA experimental point of the profile is the aftermost point of the hull ; $F n=0.26, A / L=0.01, B=180^{\circ}$.
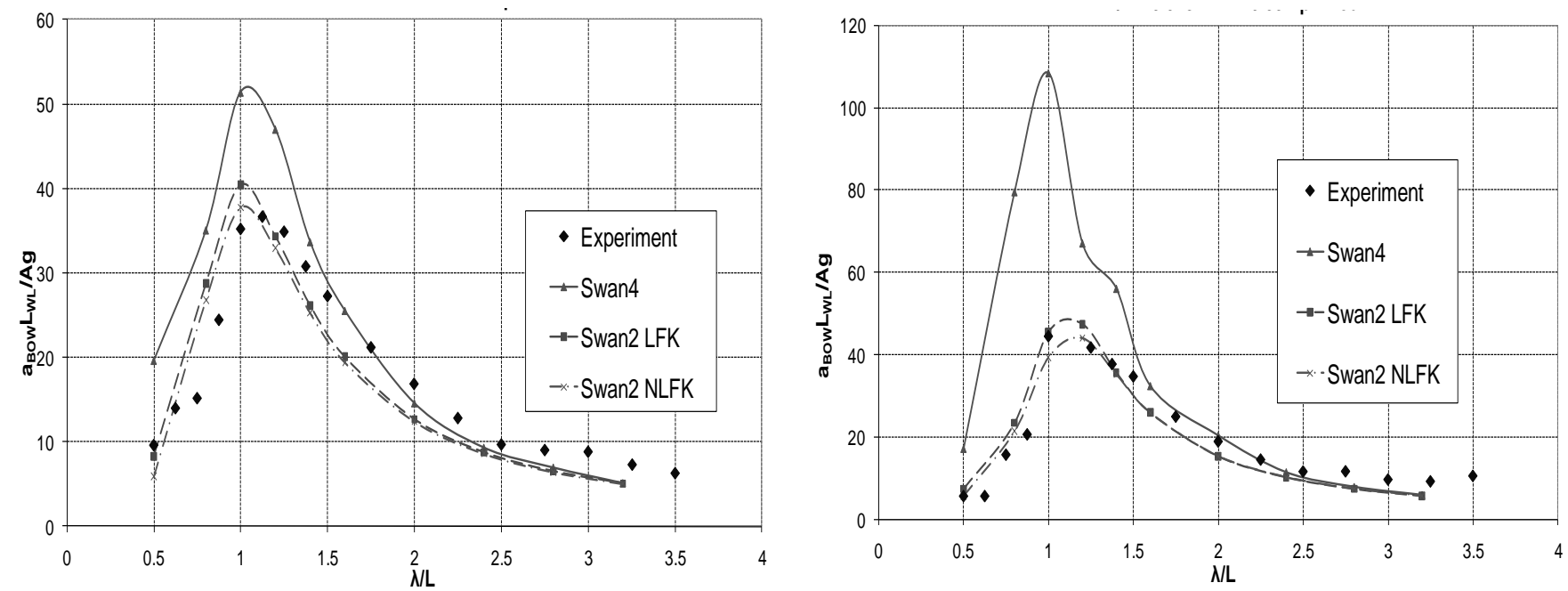

Fig. 11 RAO of vertical acceleration at the bow of the fast ROPAX hull form using all three versions of SWAN and NTUA experimental results for speeds with $F n=0.26$ (left) and 0.33 (right) $; A / L=0.01, \beta=180^{\circ}$. 

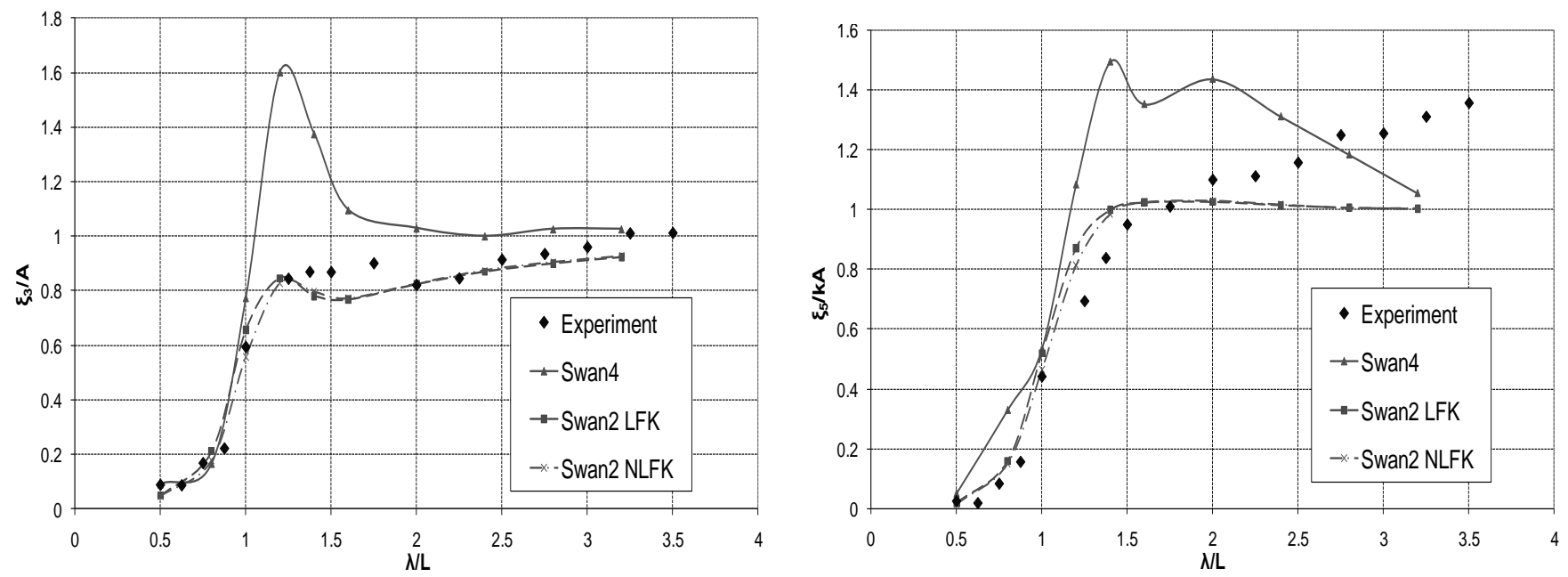

Fig. 12 Heave and pitch RAOs for the fast ROPAX hull form using all three versions of SWAN and NTUA experimental results for a speed with $F n=0.33 . A / L=0.013, B=180^{\circ}$.

Following Figs. 10 to 12 , it is obvious that SWAN4 fails to predict the experimental results except for the large wave length range. Especially, an excessive peak value is calculated for wave lengths similar to the ship length. On the other hand, SWAN2 performs better, although the agreement deteriorates significantly at the higher of the two speeds and the larger wave lengths.

\section{NTUA Series semi-planing hull form}

As a fourth and final test case the parent hull of NTUA Series of double-chine, semi-planing hull forms (Grigoropoulos et al., 2010) with wide transom are elaborated. This hull, with an $L / B$ ratio of 5.50 and, therefore, denoted as LB55 was evaluated at a relatively light displacement corresponding to a volume of displacement coefficient $C_{D L}=$ 1.61. This coefficient is defined on the basis of the waterline length $L_{W L}$ and the volume of displacement $\nabla$ by the following relation:

$C_{D L}=\nabla /\left(0.1 L_{W L}\right)^{3}$

The body plan, a perspective view of the hull form scaled by a factor of 10 compared to the tested model, is given in Fig. 13. Table 4 Main Particulars of the NTUA Series semiplaning hull form

Table 4 Contains the main particulars of the vessel.

\begin{tabular}{|c|c|}
\hline $\mathrm{L}_{\mathrm{OA}}$ & $38.33 \mathrm{~m}$ \\
\hline $\mathrm{L}_{\mathrm{BP}}$ & $35.8 \mathrm{~m}$ \\
\hline $\mathrm{L}_{\mathrm{WL}}$ & $34.97 \mathrm{~m}$ \\
\hline $\mathrm{B}$ & $6.92 \mathrm{~m}$ \\
\hline $\mathrm{T}$ & $0.97 \mathrm{~m}$ \\
\hline$\Delta$ & 69.1 tons \\
\hline $\mathrm{V}_{\mathrm{S}}$ & $24.5 \mathrm{kts}$ \\
\hline $\mathrm{C}_{\mathrm{DL}}$ & 1.61 \\
\hline
\end{tabular}
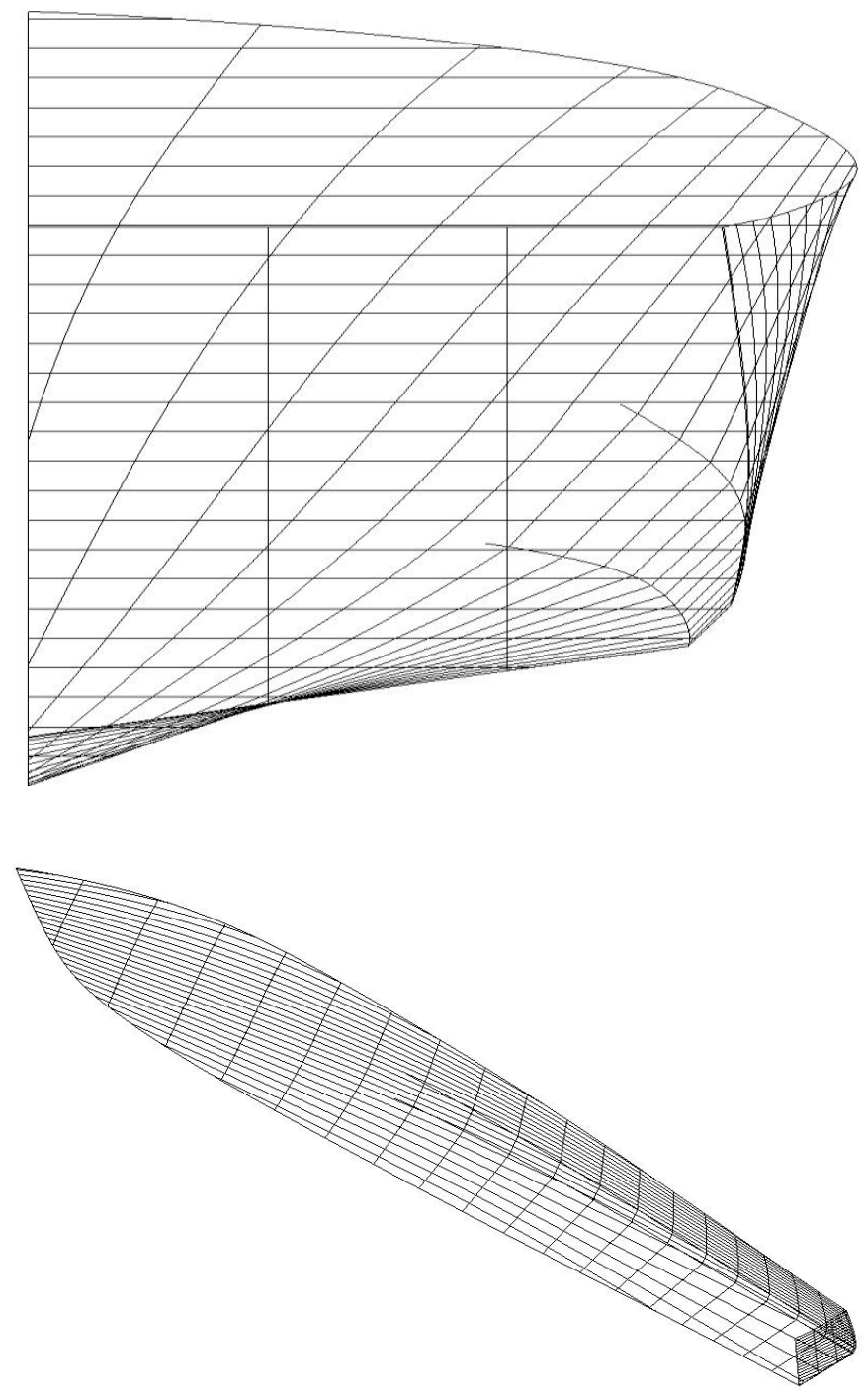

Fig. 13 Body plan, profile and main particulars of the parent hull form of the NTUA Series of planing hull forms. 
Although the geometry of this hull is not complex, the transom draught prohibits any consideration of using SWAN4. Calculations and tests have been carried out in head waves with wavelength ratios $\lambda / \mathrm{L}$ in the 0.50 to 3.80 range, for two speeds, one in the displacement mode $(F n=0.34)$ and one in the semi-planing mode $(F n=0.68)$. Furthermore, in order to investigate the effect of wave amplitude on the version of SWAN2 with the non-linear Froude-Krylov and hydrostatic forces, results for four wave amplitudes A with $A / T=0.125,0.250,0.375$ and $0.500(T=$ draught $)$ are derived. The heave and pitch RAOs for speeds with $F n=0.34$ and 0.68 are depicted in Figs. 15 and 17, respectively. The RAO of the vertical acceleration at the bow for both speeds is shown in Fig. 16.

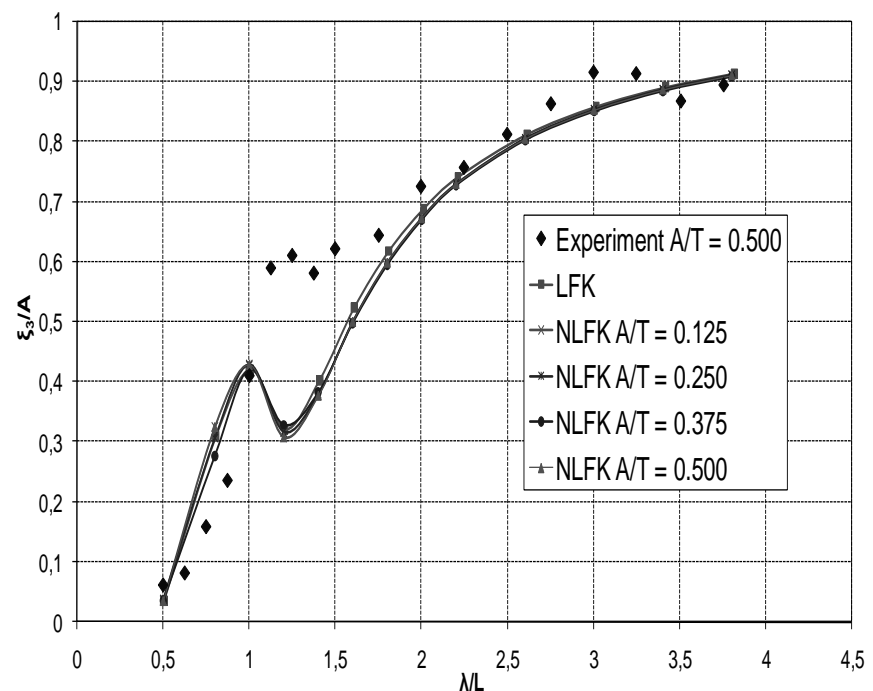

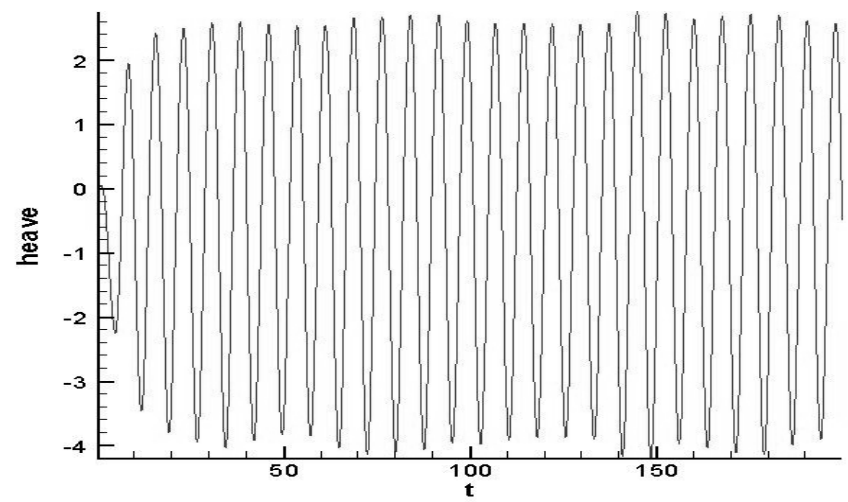

Fig. 14 Time history derived by SWAN4 for heave response of the ROPAX hull form at $F n=0.33$ and for $\lambda / L=1.40$.

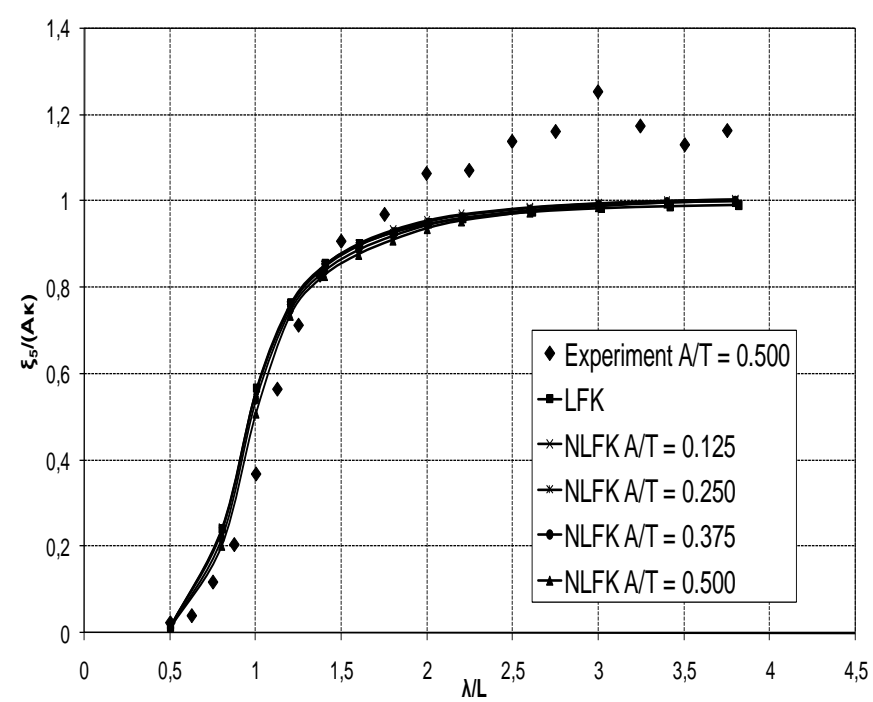

Fig. 15 Heave and pitch RAOs for the semi-planing NTUA Series hull form, using the two SWAN2 versions and experimental results at the light displacement $\left(C_{D L}=1.61\right)$ and at speed with $F n=0.34$.
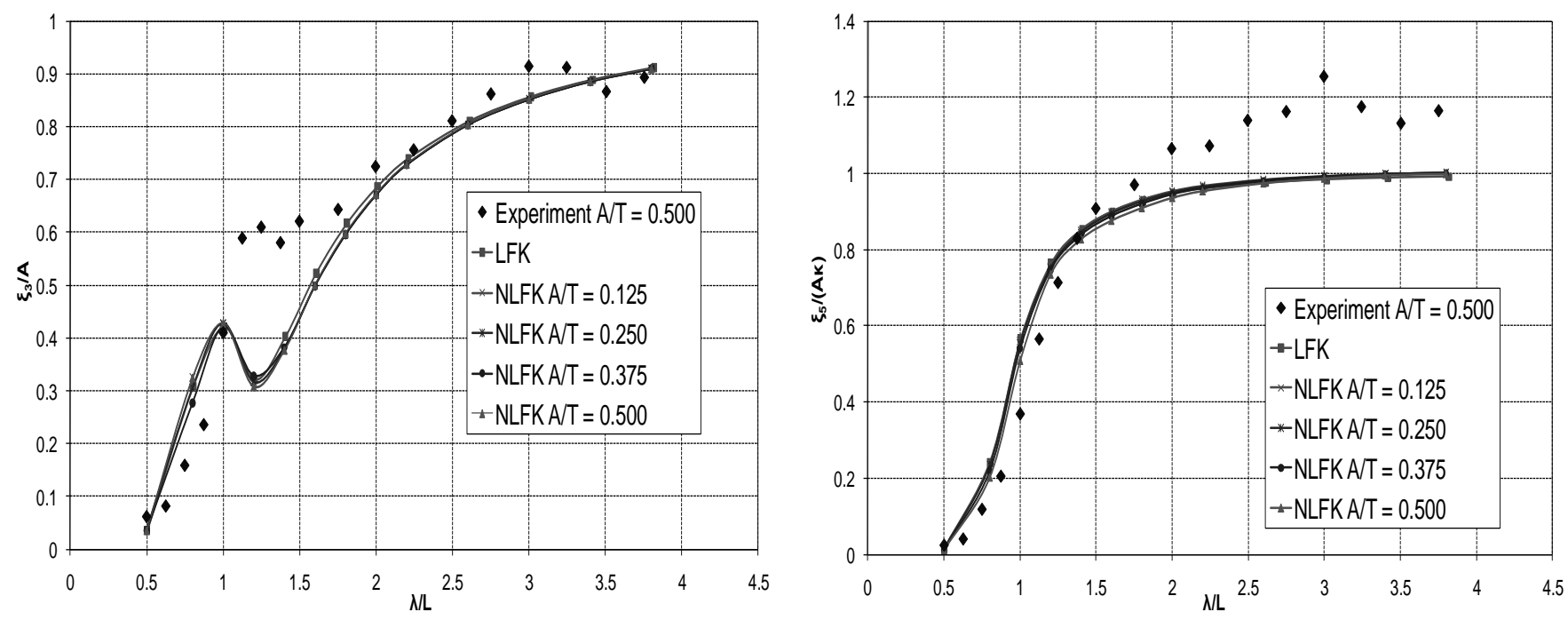

Fig. 16 RAO of vertical acceleration at the bow for the semi-planing NTUA Series hull form, using both SWAN2 versions and experimental results for $C_{D L}=1.61 \mathrm{~m}$, and speeds with $F n=0.34$ and 0.68 . 

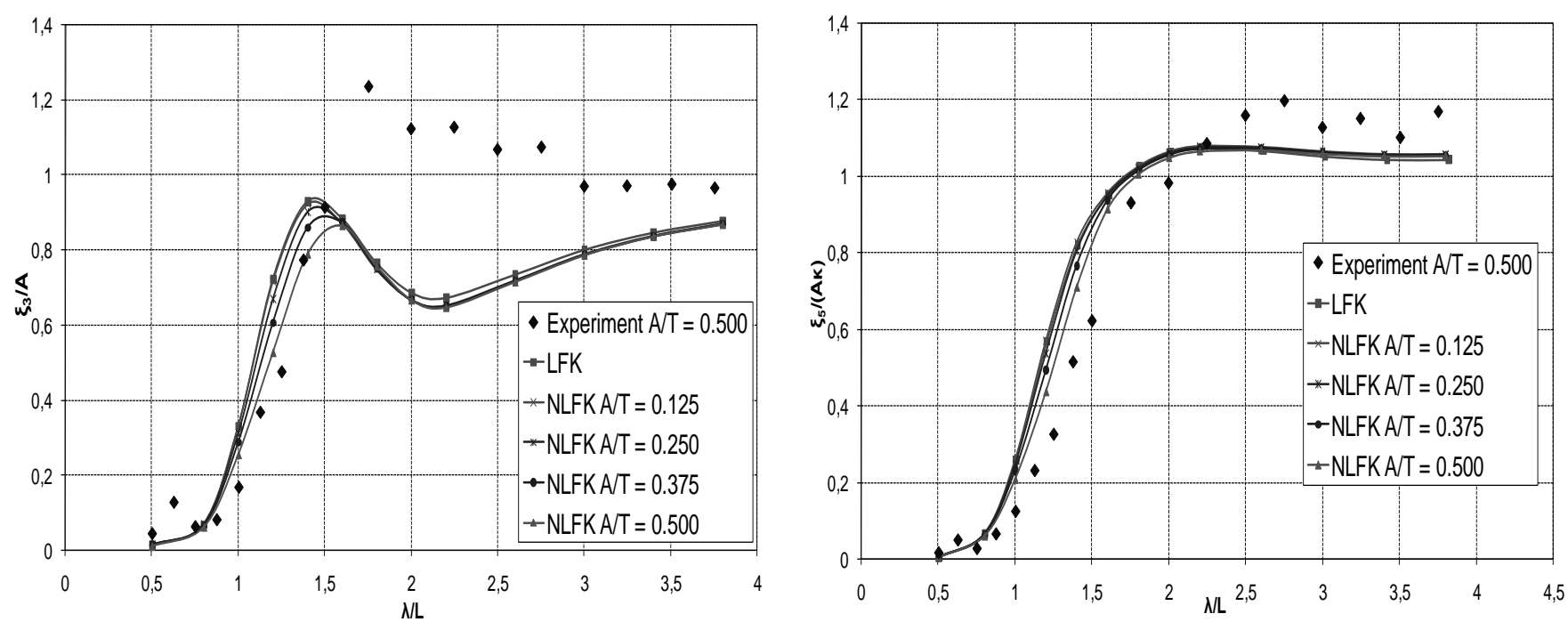

Fig. 17 Heave and pitch RAOs for the semi-planing NTUA Series hull form, using the two SWAN2 versions and experimental results for $C_{D L}=1.61$, and at speed with $F n=0.68$.

Following these figures, SWAN2 performs in general satisfactorily only in the lower speed range, where hydrodynamic lifting forces are insignificant. At the higher speed the numerical predictions for both versions of SWAN2 depart significantly from the experimental results especially in the right side of the $\lambda / L$ axis. Furthermore, the option of using the non-linear F-K and hydrostatic forces improves the numerical predictions.

\section{DISCUSSION AND CONCLUSIONS}

In this paper a linear time-domain 3-D panel method, an advanced version of it where the non-linear Froude-Krylov and the hydrostatic forces are used, and a fully non-linear panel method were evaluated via three test cases with increasing geometric complexity. Additional tests have been carried out using the first two methods for a lightdisplacement planing hull form at displacement and semiplaning speeds.

Numerical calculations have been carried for at least two speeds in each case and for a set of wave amplitudes in the case of the planing hull form. In all cases, the computational results were evaluated on the basis of available experimental results and are presented in the figures of section 2 of this paper.

Following these graphs, it is concluded that both versions of SWAN2 the linear and the one with the non-linear FroudeKrylov and hydrostatic forces provide a more robust tool for prediction of the dynamic response of the vessels than the non-linear version. In general, their results are close to what was expected on the basis of experience. Furthermore, the use of the option of non-linear Froude-Krylov and hydrostatic forces is beneficial for the accuracy of the predictions.

On the other hand, the fully non-linear version of the code does not produce in all cases reasonable results, especially in shorter wave lengths up to ship's length. Only in some limited cases the non-linear version produces results in close agreement with the experimental ones, while in other cases the numerical solution departs significantly from the experimental results.

Finally, it should be noted that both SWAN2 and SWAN4 are time domain codes. Thus, the RAOs are derived from time histories using Fast Fourier Transform (FFT). The time histories of the responses derived by SWAN4 were not always purely sinusoidal, although the inputs were always sinusoidal waves. In some cases time histories as the one presented in Fig.14 were derived. In these cases the final result is sensitive to the length and the location of the window sampled for a FFT analysis. Discrepancies of the order of 5\% are observed between different size and location of the windows.

\section{REFERENCES}

Athanassoulis, G.A. and Loukakis, T.A., 1982. An extended lewis form family of ship sections and its applications to seakeeping calculations. International Shipbuilding Progress, 32(366), p.33.

Frank, W., 1967. Oscillation of cylinders in or below the free surface of deep fluids. Naval Surface Resarch and Development Center, Report No. 2375, Washington D.C., USA.

Gerritsma, J. Beukelman, W. and Glansdorp, C., 1974. The effects of beam on the hydrodynamic characteristics of ship hulls. Proceedings of the 10th Symposium On Naval Hydrodynamics, Cambridge, MA, USA

Grigoropoulos, G.J., 2004. Hull Form optimization for hydrodynamic performance. Marine Technology, 41(4), pp.167-182. 
Grigoropoulos, G.J. and Chalkias, D.S., 2005. Hull-form optimization of high-speed monohulls. Proceedings of the $8^{\text {th }}$ International Conference on Fast Sea Transportation FAST 2005, St. Petersburg, Russia.

Grigoropoulos, G.J. Damala, D. and Loukakis, T.A., 2010. Dynamic performance of the NTUA Double-Chine series hull forms in regular waves. Proceedings of the $2^{\text {nd }}$ Chesapeake Power Boat Symposium, Annapolis Maryland, USA.

Guevel, P. and Bougis, J.,1982. Ship motions with forward speed in infinite depth. Intlernational Shipbuilding Progress, 29(332), p.103.

Huang, Y., 1997. Non-Linear Ship Motions by a Rankine Panel Method. Ph.D. Thesis, MIT, Cambridge, MA.

Katsikis, C., 2009. Seakeeping computations for ships using a non-linear code. Diploma Thesis, NTUA, Athens, Greece.

Kim, K.-H. and Kim, Y., 2009. Time-domain analysis of nonlinear ship motion responses based on the weakscatterer hypothesis. Proceedings of the 19th International Offshore and Polar Engineering, Osaka, Japan.

Korvin-Kroukovsky, B.V. and Jacobs, W.D., 1957. Pitching and heaving motions of a ship in regular waves. Transactions SNAME, 65, p. 590.

Kring, D.C., 1994. Time Domain Ship Motions by a ThreeDimensional Rankine Panel Method. Ph.D. Thesis, MIT, Cambridge, MA.
Kring, D.C. Huang, Y. and Sclavounos, P., 1995. Time domain ship motions with a nonlinear extension. Proceedings of the $10^{\text {th }}$ International Workshop on Water Waves and Floating Bodies, Oxford, UK, pp. 135138.

Kring, D.C. Huang, Y. Sclavounos, P. Vada, T. and Braathen, A. 1996. Nonlinear ship motions and wave induced Loads by a Rankine Panel Method. Proceedings of the $21^{\text {st }}$ Symposium on Naval Hydrodynamics, Trondheim, Norway.

Lewis, F.M., 1929. The inertia of water surrounding a vibrating ship. Transactions SNAME, 37, p. 1.

Liapis, S.J., 1986. Time Domain Analysis of Ship Motions. Technical Report 302, Department of Naval Architecture and Marine Engineering, The University of Michigan, Ann Arbor, MI.

Sclavounos, P.D., 1996. Computation of Wave Ship Interactions. Advances in Marine Hydrodynamics, ed. by M. Ohkusu, Computational Mechanics Publications.

Ursell, F., 1949a. On the heaving motion of a circular cylinder on the surface of a fluid. Journal of Mechanics and Applied Mathematics, 2, p. 213.

Ursell, F., 1949b. On the rolling motion of a cylinders in the surface of a fluid. Journal of Mechanics and Applied Mathematics, 2, p. 335. 